\title{
How Cycling is Perceived in Budapest Based on Household Survey Results
}

\author{
Tamás Mátrai ${ }^{1 *}$, János Tóth¹, Julio Cruz ${ }^{1}$ \\ 1 Department of Transport Technology and Economics, Faculty of Transportation Engineering and Vehicle Engineering, Budapest \\ University of Technology and Economics, H-1111 Budapest, Műegyetem rkp. 1-3. \\ * Corresponding author, e-mail: tamas.matrai@mail.bme.hu
}

Received: 11 September 2019, Accepted: 28 February 2020, Published online: 31 March 2020

\begin{abstract}
With the increasing awareness of ecosystem limitation, cycling, as a transportation mode, has been promoted as an approach to preserve our resources of raw materials and encourage healthier habits in our everyday lives.

Aiming to gather data about cycling in Budapest and its agglomeration, a random walk based household survey with 1511 individuals was carried out. Two main groups were targeted during the household survey: citizens who have used their bicycle for transportation in the past 30 days $(n=672)$ and those who are willing to use bicycles given the right circumstances $(n=839)$. After the general household related questions, the main part of the questionnaire explored cycling behavior through 7 questions. It was possible to value parameters such as cycling impacts in society, cycling infrastructure development and its spatial behavior, perceived safety, morale, safe infrastructure, facilities, cost sensitivity and the impact of dedicated cycling infrastructure in Budapest.
\end{abstract}

\section{Keywords}

household survey, cycling, mode choice, route choice, cycling infrastructure

\section{Introduction}

The constant effort to attain economic growth in contrast with the awareness of the fragility of natural resources and their limitations have made the society to develop and implement a more sustainable way of living [1]. Having global environmental sustainability, Western health concerns, obesity and social inequality challenges as a background, cycling has been regularly and widely promoted as an initiative [2]. Modernized and urban lifestyles have faded away physical activity of everyday life, and this has resulted in a threat to population health caused by sedentary lifestyles [3]. It is estimated that physical inactivity causes $21-25 \%$ of the disease burden and even greater proportions for diabetes (27\%) and ischaemic heart disease (30\%) [4].

The use of bicycles has established relationships within the social, cultural and economic spheres [5]. According to the International Transport Forum (ITF), which is an intergovernmental organization with 59 member countries including Hungary, bicycles can contribute to sustainable urban mobility in a range of ways: by not using fossil fuels, not creating air pollution or noise pollution, providing useful exercise for cardiovascular health and contributes significantly to enhancing cities' livability [5]. Furthermore, bicycles are inexpensive and provide door-to-door mobility over distances that account for a large proportion of urban travel, i.e. over distances of about $5 \mathrm{~km}$ [6].

As the popularity of cycling as a mode of transport inside cities is growing, FLOW (Furthering Less Congestion by Creating Opportunities For More Walking and Cycling, H2020 project, grant agreement No. 635998) focused on the congestion reduction benefits of walking and cycling; has conducted a study using questionnaires to understand the preferences of travelers, the limitations of each transport mode and the expectations of the interviewed people, considering that a detailed investigation can help to decide which measures can increase the proportion of cycling [7]. Thanks to infrastructure developments, the possibility of bicycle rides is being improved. Besides this, many other features affect travel behavior, which can vary from city to city. The answers of the FLOW questionnaire show the preferences of travelers, the limitations of each transport mode and expectations of the interviewed persons [8].

The potential benefits of increasing the levels of walking and/or cycling [9] are substantial, and questionnaires have been used to bring up its overall benefits and drawbacks. For 
example, questionnaires in the UK have differentiated considerably cycling levels and rates of change. This offers the opportunity to analyze whether those areas that have successfully reached a modal shift towards cycling have also generated cycling behavior that is equally balanced [10].

As cycling increases, cultural norms standardized by society may take time to change the situation towards gender equity. As an example of this, a more "female-friendly" cycling environment (e.g. in terms of more protected infrastructure, or a greater normalization of cycling) could captivate a greater number of women as "early-adopters". These patterns imply the necessity of creating new policies which could increase the preference and the consideration of cycling as a mean of transport for under-represented groups [10]. However, it cannot be assumed that growing cycling levels (characteristic of many dense urban areas) will automatically increase the gender and age diversity of cyclists. What could really be considered is that a more supportive cycling environment for women and elderly people might bring about a threshold effect. The cycling environment would comprise a range of factors, but given the notoriety of safety concerns among barriers to cycling, goodquality routes and infrastructure must be high on the list [10].

The citizens day by day meet traffic jams and other disturbances in transport. Despite the bad circumstances, travel demands do not decrease, because the permanent motivation for journeys (home- or work-based trips) are constantly present $[11,12]$. Cycling and public transport are generally seen as substitutes from the perspective of a single trip: a person either walks, cycles, drives or takes a bus, train or tram to their destination. However, this concept overlooks multi-modal trips where people can access a train station by using bicycles (or accessing their destination from a train station) [6].

Kager and Harms [13] explain how cycling and public transportation can be effective complements rather than competitors. Cycling appears to be limited in its practical scope, but is highly flexible in terms of destination and travel timing. Public transport (especially rail) can cover larger distances with high capacity, but because it operates on scheduled lines, public transport suffers from destination inflexibility and travel time. From the perspectives of an individual traveler and of the overall transport system, there are strong gains to be made by combining each mode's strengths. Compared to walking, cycling allows users of public transport to access more remote public transport stops and stations. This would mean that a small amount of time could be saved for a given configuration of the trip. However, the real power of enabling public transportation users to cycle (instead of walking) to public transportation is that they can access a wider range of stations for any given travel time, allowing users to optimize their entire journey to better suit their needs [13].

A traffic survey helps us to learn about the needs and reactions of travelers to changes of travel conditions. Traffic counting is the most obvious way to record travel demand, but knowing the traffic volume is not enough to understand deep relationships and causal links in passenger transport. The aspects of travel behavior in cities can change, which can be investigated by interviews, especially through household surveys. Stated preference and revealed preference methods can shed light on the motivation for mode and route choice [14, 15].

Cycling is beneficial for the economy, offers environmental and health character compensations, which allow citizens to have a healthier lifestyle and it also positively contributes to the conditions of public transportation [16]. Among other factors, two decisive attributes for a better integration between bicycles and motor vehicles must be mentioned: (i) public safety in the road and (ii) safe cycling infrastructure [17].

Given these widely documented positive benefits, cycling downtown, for example, can be correlated with health and safety risks due to potentially high levels of exposure to air pollution, road noise and high traffic density [18], as cyclists often ride on roads shared with motor vehicles or on cycle routes parallel to or near main roads [19]. In addition, as Int Panis et al. [20] note, cyclists often have much higher respiration rates due to their physical activity than those traveling by car (ventilation for cyclists is 4.3 times higher than for car drivers). Consequently, over the same period, they inhale more air pollutants.

Even "cyclist" is a heterogenic group; therefore, during the planning process, the needs of the different user segments have to be taken into account. This statement was proved in a cycling survey carried out by the Wellington City Council between March and June 2014. Hesitant cyclists, those who are very unlikely to cycle under current cycling conditions, represented $9 \%$ of the weighted sample. Those who use bicycles for recreational purposes represented $17 \%$. Likely cyclists made up $12 \%$ - they are likely to cycle under the current cycling conditions. Safe cyclists, who are strongly oriented towards cycling, represented $33 \%$ of the weighted sample. Most respondents think that to increase cycling demand in Wellington City, the most important feature to be improved is the cycling infrastructure [21]. 
In the 1990s and at the beginning of the 2000s, the engineering approach was the main ideology among transport professionals. This favored the separation of the different transport modes, including the separation of interchanges, as these solutions seemed to be the safest and these provided the highest possible capacity. The continuing practice of outdated urban planning projects have caused many problems to large cities. Such projects focused on polluting and individualistic transport that causes various problems for the population of these regions. This car-centric view has been changed in the last decade, especially with the wide adaptation of new types of planning approaches like Sustainable Urban Mobility Planning (SUMP). This citizen-centered approach promotes the right mixture among different transport modes. Furthermore, the new approach promotes shared spaces, as these types of infrastructure can create livable public spaces, not just surfaces for transport. At the same time, it seems that shared spaces and this "liberal" thinking only works in countries where the transport morale is high, and the transport participants are aware of each other.

As Berki [14] and Buehler et al. [22, 23] argued, one of the greatest obstacles for cycling is the perceived danger of cyclists. Furthermore, they stated that the higher the separation between motorized traffic and cyclists is, the higher the safety for cyclist should be. Thus, providing more dedicated cycling infrastructure can increase the level of bike usage. Although as DiGioia et al. [24] state, there is limited research on the impact of different measures toward cycling safety based on before-after crash data. At the same time, Monsere et al. [25] stated that perceived safety and user perception is more important related to cycling related decisions than objective measures of safety.

In this article we will present a survey related to cyclist route and mode choice decisions in Budapest, Hungary and its implications to cycling safety. Other policy implications are also discussed.

\section{Methods}

BKK Centre for Budapest Transport (henceforth the BKK), the mobility manager of the city of Budapest is responsible for the maintenance and development of the Macroscopic Transport Modell (MTM) of Budapest and its agglomeration [26]. Within the framework of the FLOW project where the main goal was to put walking and cycling on an equal footing with motorized modes as a solution to tackle urban congestion, by developing a user-friendly methodology to assess the effectiveness of walking and cycling measures [27] - the BKK has procured a household survey, organized manual cyclist counting and installed automated cyclist counters. The household survey sample has been divided into two separate parts; both were conducted by the CAPI (computer assisted personal interview) method. The first part was a stated preference survey, where the interviewee had to choose between different transportation modes in several situations $(n=3507)$. The second part was a simple questionnaire about the cycling habits and preferences $(n=1511)$. In this article we will only present the second - simple behavior - survey and the results.

We used the stratified sampling methodology; the 23 districts of Budapest were used as a stratum. A simple random walk sampling process was then used in each district with preselected questions related to cycling habits. As we wanted to gather information about the cycling habits, our main target group was citizens who have used bicycle for transportation in the last 30 days. The second target group was made up of those willing to cycle given the right circumstances. Those who did not belong to any of the above groups were not interviewed.

The same socio-demographic clustering questions were used as in all the similar surveys in Budapest, which are the following. Information gathered about the household: location; size; average income; number of different vehicles. Information about the individuals: gender; age; highest qualifications; type of employment; type of driving licenses; frequency of driving; availability of public transport pass and MOL Bubi (the public bike sharing system at Budapest) subscription; usage of bike; usage of mobile phone and trip planners.

The first step of our analysis was to check the sample itself. The sample size was 1511 individuals, out of whom 672 used a bike in the previous month (from now on referred as "cyclist"); 839 stated willingness of cycling (from now on referred as "potential cyclist"). The collected sample was compared to the 2011 census data regarding to the districts (Fig. 1) in Budapest and to the population aged between 20 and 65 (Fig. 2), as well as to gender (Fig. 3).

In the next step, the collected data were organized in different graphs in order to visualize the results. These graphs helped us to find patterns and draft hypotheses. Ten major observations were made.

The mean and standard deviation were computed and presented as the descriptive statistics of the answers. Four main observations were supported by these descriptive statistics and we derived several smaller insights. 


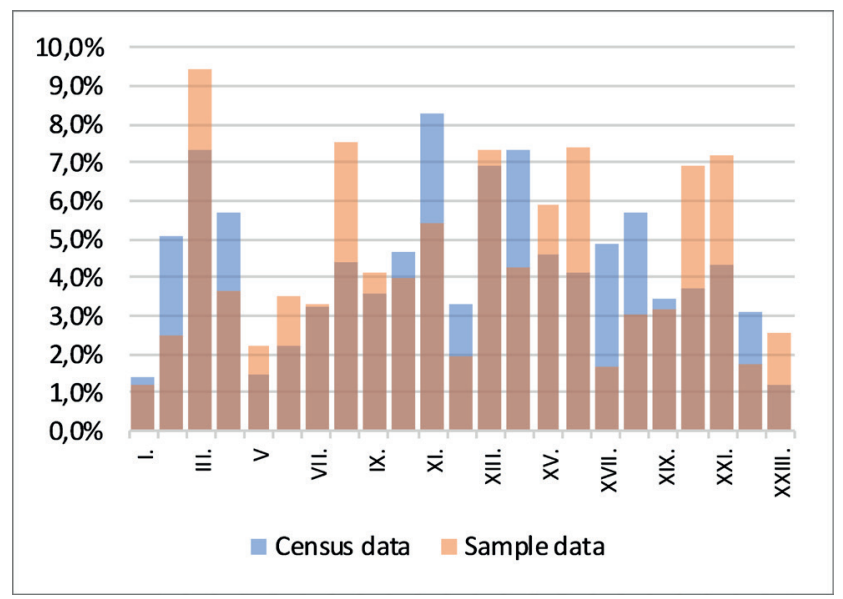

Fig. 1 Distribution of the sample within districts of Budapest $(n=1511)$

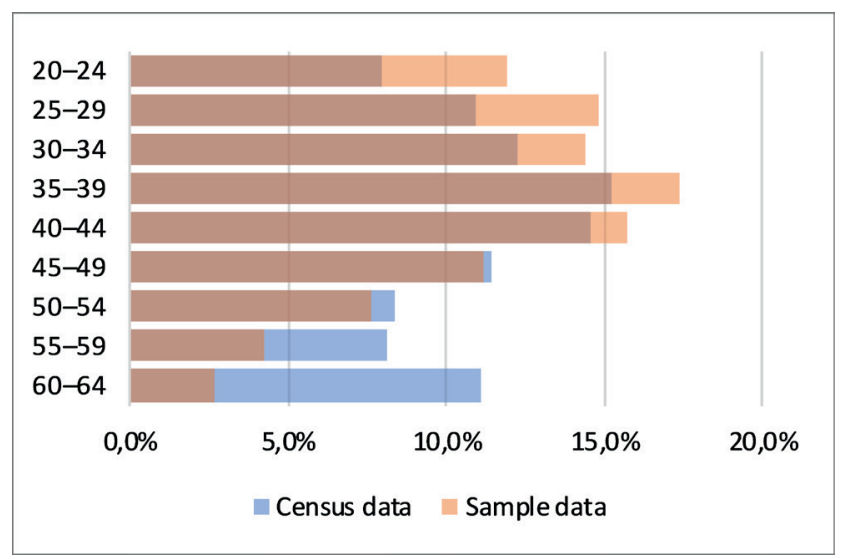

Fig. 2 Distribution of the sample within age groups $(n=1511)$

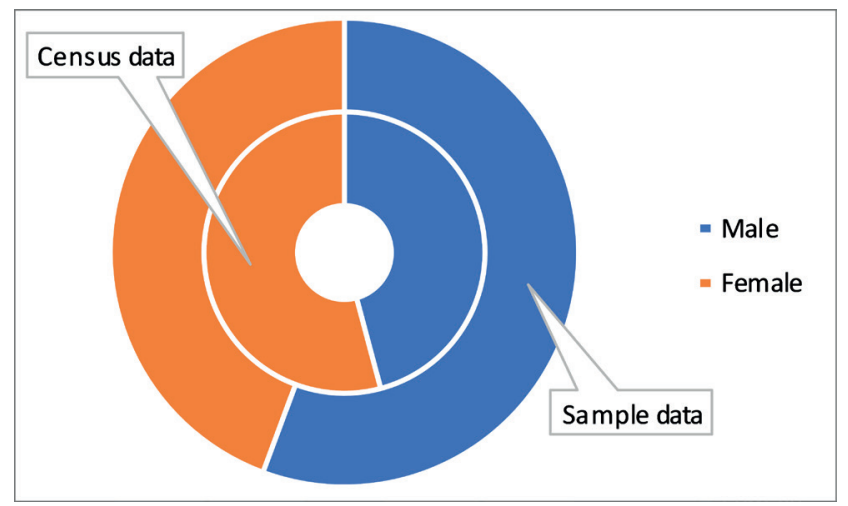

Fig. 3 Distribution of the sample within gender $(n=1511)$

Six hypotheses were tested by the Chi-Square Test. This test was applied to determine the relation between two sets of parameters, as most of the answers were nominal ones [28].

One hypothesis was formulated related to the stated maximum cycled distance. A one-way ANOVA test was applied to this continuous variable [28].

\section{Results and discussion}

The main part of the questionnaire explored cycling behavior through 8 questions.

In the first question the request was to evaluate cycling in Budapest in general (Fig. 4). The scale used here ranged from -3 (very bad) to +3 (very good). The same question was asked from the users and the potential users $(n=1511)$. The environmental impact was the highest evaluated impact of cycling, with less than $10 \%$ negative value. Comfort and safety and security were evaluated below zero by most of the respondents, which suggests a low level of cycling culture and/or infrastructure in Budapest.

Both groups (cyclists and potential cyclist) were asked about cycling in general in Budapest from different aspects. The first hypothesis with Chi-Square test was that the two groups should answer significantly differently to this question. This hypothesis proved to be true, as all tests showed high significance $(\mathrm{p}<0.01)$. It can be interpreted that there is a significant difference between the views of users and those of potential users. On the other hand, a more likely scenario is that the user interpreted the question in a way that it reflected their own cycling activities not cycling in general.

The second question concerned the different cycling related activities which happened in the previous two years (2014-2015) and how those affected the cycling willingness of the respondent (Fig. 5). The four activities were the following: Cycling infrastructure development (BKK significantly developed all cycling infrastructure aiming to form a comprehensive network); Critical Mass (a movement, whose goal is to raise awareness of cycling with mass events); car free day during the European mobility week (which is an annual initiative of the European Commission for Sustainable Urban Mobility since 2002,

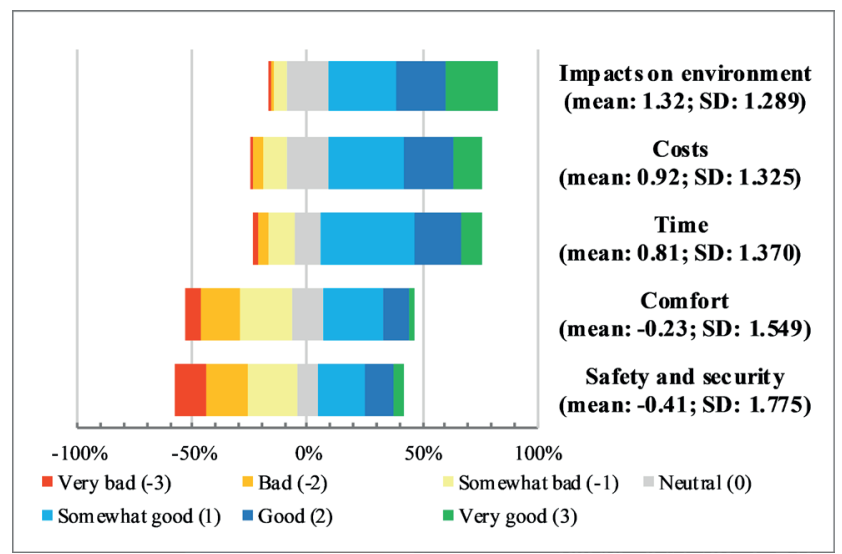

Fig. 4 Cycling in general in Budapest from different aspect $(n=1511)$ 


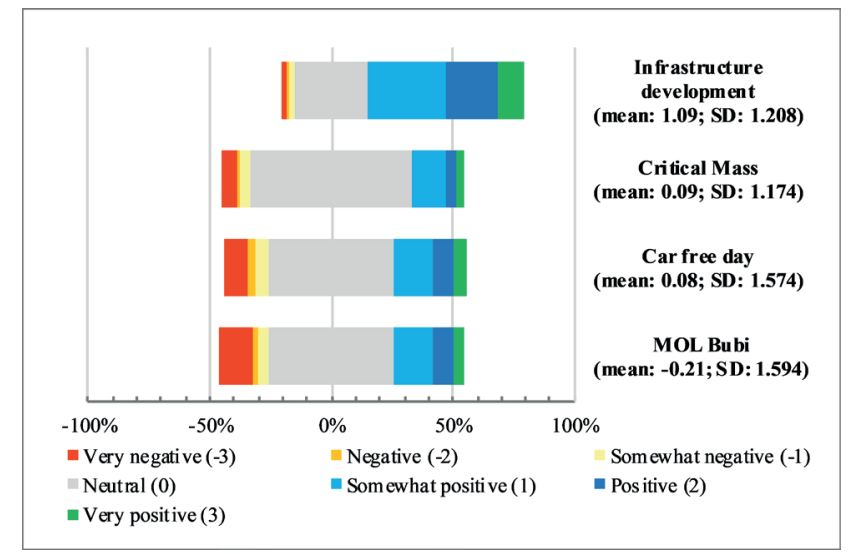

Fig. 5 Importance of different activities related to attractiveness to cycling $(n=1511)$

including traffic-related events, such as temporary closures of streets for cars); and MOL Bubi system developments. The scale used ranged from -3 (very negative) to +3 (very positive). The same question has been asked from the users and the potential users as well $(n=1511)$. Based on the presented question, the respondents were close to neutral. This either means that they were not affected by these actions or that the question was not appropriate to capture their response.

Potential users $(n=839)$ were asked how the different aspects affect their willingness of cycling (Fig. 6). The scale was designed from -3 (would not encourage) to +3 (very encouraging) and the 0 was indifferent. The aspects were the following:

- better traffic behavior and morale,

- safer cycling infrastructure,

- direct infrastructure between the origin and the destination,

- more, safer bicycle parking facilities around Budapest,

- increase of the public transport fees,

- higher petrol prices,

- higher parking fees,

- introduction of the congestion charge.

The potential users value perceived safety the highest, it can be seen in morale and safe infrastructure parameters. They also value the cycling related facilities high. At the same time, they seemed to have low cost sensitivity (the last 4 parameters) with high differences in the given scores.

Due to the involvement of categorical variables, a ChiSquare Test was applied. The second hypothesis was that there is a relation between the average household income category and the price changes aspects related to willingness to cycling. None of the car related elements (increase of parking fees: $p=0.484$, increase of petrol prices:



Fig. 6 Importance of different factors related to willingness to cycling

$$
(n=839)
$$

$p=0.162$, introduction of congestion price: $\mathrm{p}=0.763$ ) showed high enough significance to accept this hypothesis. Only the public transport $(\mathrm{PT})$ price increase $(\mathrm{p}=0.036)$ was significant, but it was not convincing.

There was another parameter on which a third hypothesis was formulated: it was expected that the main transport mode has a significant affect on cost sensitivity. This proved to be true as the preferred transport mode showed high significance related to all the above-mentioned aspects $(\mathrm{p}<0.001)$.

There was an additional question for the potential users $(n=839)$, which was related to the willingness of usage of the MOL Bubi system and how the different interventions can affect it (Fig. 7). As we are speaking of potential users,

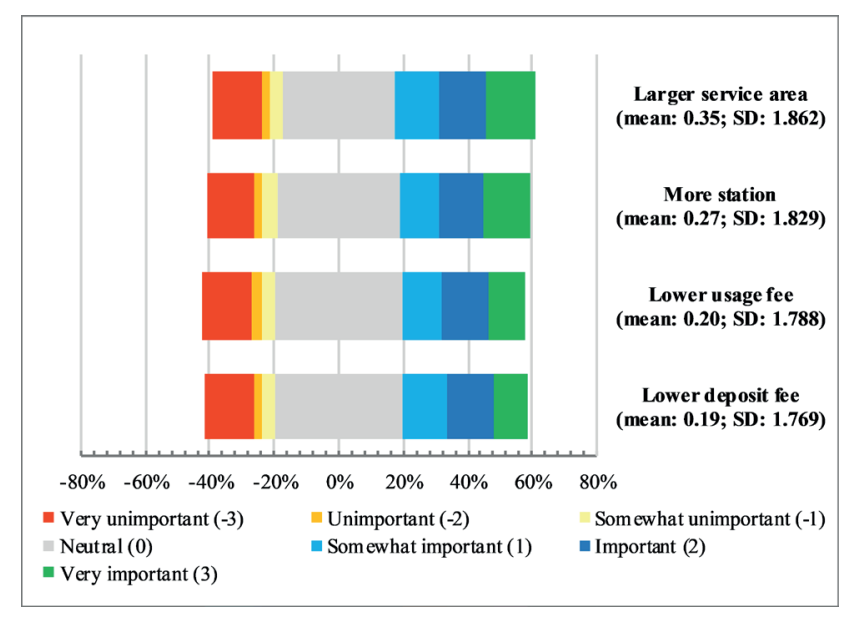

Fig. 7 Importance of different factors related to willingness of usage MOL Bubi $(n=839)$ 
the scale was erroneously designed from -3 (very unimportant) to +3 (very important) and the 0 was indifferent. The answers suggest the already known theorem according to which for surveys using attitude questions, respondents cannot provide meaningful answers if the different imaginary alternative solutions are not described in sufficient detail. Furthermore, the large number of -3 answers suggests that most likely this question and the related answers were compiled in a confusing way, since several respondents gave it a neutral value.

In the fifth question the cyclists $(n=672)$ were asked to order (rank) the following aspects of mode choice based on their importance (where 1 was the most important and 4 was the least important):

- can reach the destination in a safe environment,

- can reach the destination through a direct route (with the shortest distance),

- can reach the destination through the quickest route (with the shortest time),

- can reach the destination in a nice environment.

The most important parameter based on this question is again perceived safety. It also can be noted that the respondents value lower mileage more than lower travel time (Fig. 8).

In the sixth question (Fig. 9), the respondents were asked to evaluate the importance of different factors related to their mode choice towards cycling. This section was presented only to those who cycled in the last month $(n=672)$. The scale used was from -3 (very discouraging) to +3 (very encouraging). The factors were the following:

- weather,

- number of destinations on the given day,

- trip purpose,

- cycling infrastructure between the origin and destination,

- distance,

- bike parking facilities at the destination,

- changing facilities at the destination,

- terrain (e.g. slopes).

All the previously described aspects affect the mode choice. The weather, the trip purpose and the number of daily destinations were considered the most important. At the same time, the terrain and the change facilities were the least significant. $70 \%$ of all respondents gave above 0 points for parameters except for the two least significant ones. The standard deviation of all parameters is between 1.34 and 1.67, i.e. the users are experiencing these factors similarly.

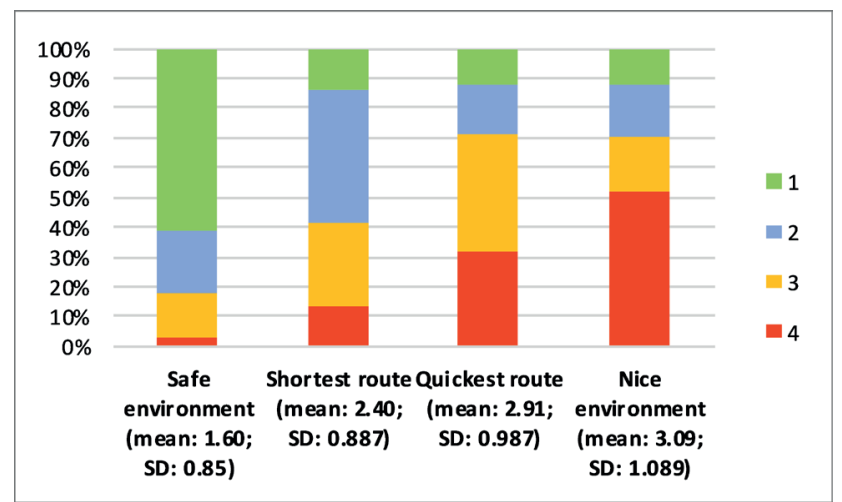

Fig. 8 Ranking the different aspect in mode choice $(n=672)$

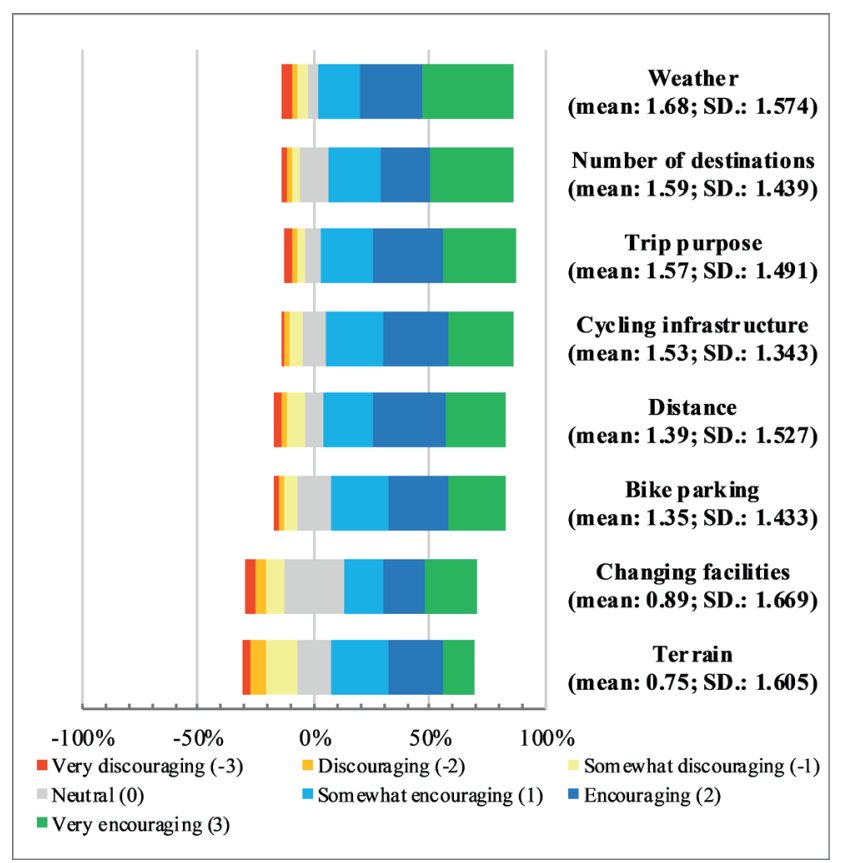

Fig. 9 Importance of different factors related to mode choice $(n=672)$

In the seventh question, 9 different types of cycling infrastructure were shown with pictures to the respondents and the request was to evaluate these ones from comfort and safety points of view. This task was only given to the cyclist group $(n=672)$. The scale was from -3 (very bad) to +3 (very good). See the results are summarized in Table 1, ordered from the least traffic to the most traffic (rows 1-3) and from the least separation to the most separation (row 4-9).

The fourth hypothesis was that the perceived comfort and safety of the same type of cycling infrastructure is highly correlated. This proved valid as the significance level of all 9 cases were $p<0.001$. It means that a complex notion as comfort is most likely to incorporate the safety aspect.

A group has been created selecting the male cyclist under $35(n=181)$ and their responses were compared to the answers of the entire population $(n=1511)$. It was 
Table 1 Results related to different infrastructure types

\begin{tabular}{|c|c|c|c|c|c|c|}
\hline \multirow{2}{*}{ \# } & \multirow{2}{*}{ Picture } & \multirow{2}{*}{ Type of street } & \multicolumn{2}{|c|}{ Comfort } & \multicolumn{2}{|c|}{ Safety } \\
\hline & & & Mean & SD & Mean & SD \\
\hline 1 & & Residential street & 1.24 & 1.468 & 1.08 & 1.595 \\
\hline 2 & & Two lane $(2 \times 1)$ street with average traffic & 0.19 & 1.650 & -0.23 & 1.671 \\
\hline 3 & & Multiple lane layout with large traffic & -0.71 & 1.805 & -1.25 & 1.641 \\
\hline 4 & & Contraflow cycling in the street & -0.48 & 1.689 & -0.83 & 1.769 \\
\hline 5 & & Common bus and cycling lane & 0.34 & 1.785 & -0.10 & 1.751 \\
\hline 6 & & Cycling lane & 1.76 & 1.292 & 1.64 & 1.403 \\
\hline 7 & & Common pedestrian and cyclist path & 1.15 & 1.375 & 0.84 & 1.411 \\
\hline 8 & & Separated pedestrian and cyclist path & 1.88 & 1.177 & 1.85 & 1.240 \\
\hline 9 & & Individual, separated cycling lanes & 2.66 & 0.823 & 2.65 & 0.887 \\
\hline
\end{tabular}


expected that the younger male group can see the safety of certain type of infrastructure differently than the rest of the population. There was significant difference in the evaluation of contraflow cycling $(p=0.001)$ and common bus and cycle lane $(p=0.013)$.

There was a group of questions in the Budapest survey related to the route choice aspect of cyclists $(n=672)$. Ten situations were presented out of which 6 were related to the terrain (Fig. 10) and 4 were related to the surface (Fig. 11). The respondents had to evaluate a situation in a -3 (very uncomfortable) to +3 (very comfortable) scale.

The different situations related to cycling on different terrains was (Fig. 10):

- a small slope (1-5\%) upwards,

- a medium slope (5-10 \%) upwards,

- a hard slope (>10\%) upwards,

- a small slope (1-5\%) downwards,

- a medium slope (5-10\%) downwards,

- a hard slope (>10\%) downwards.

The results are similar to the expectations. Going upwards, only the hard slope has a significant negative value. At the same time, going downwards the value also declines when the slope is increasing, most likely because of fear from the high slope. The large standard deviation can suggest that the results are different in different user groups.

It was also expected that male cyclist under $35(n=181)$ is less affected by the slopes than the entire population $(n=1511)$. This proved to be valid, for 5 out of 6 occasions. This group behaves the same in the situation of cycling upward in a very hard slope, but differently in all the other cases.

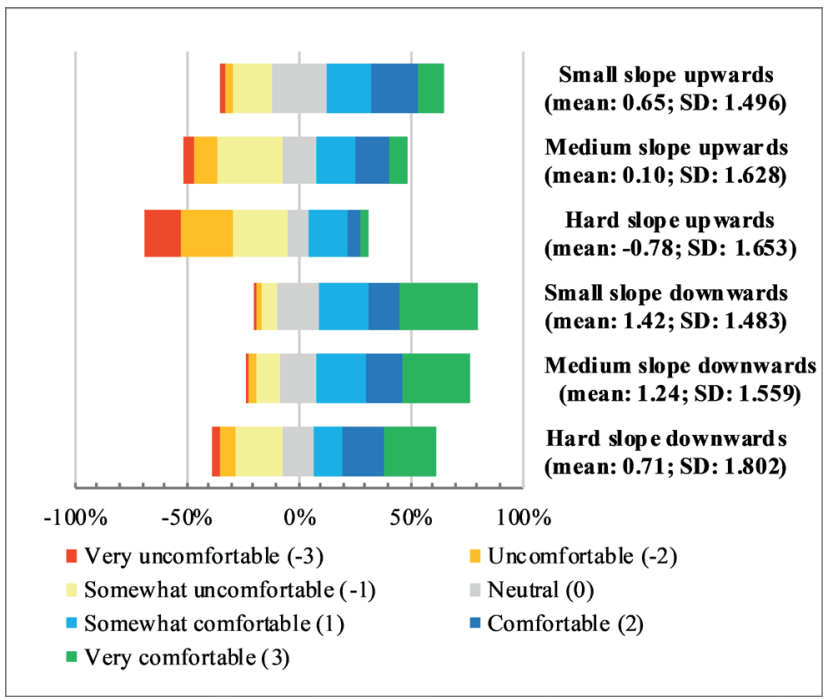

Fig. 10 Comfort of cycling in different terrain $(n=672)$
The different situations related to cycling on the following surface was (Fig. 11) good asphalt; paving stone; cobble stone; deteriorated asphalt with potholes. The most evident obstacles to cycling are poorly designed or maintained roads (debris or a poor surface). This is followed by how much the cyclist are exposed to risks and how much the drivers alongside the road are unsafe when driving regarding to assortment of other barriers such as: poor lighting, a route that is slippery when wet, whether or not it is raining, and the need to transport bulky items.

Economic development and growth and social benefits have been constantly contributed to the income generated by the roads and transport. Poorly maintained roads constrain mobility, significantly raise vehicle operating costs, increase accident rates and their associated human and property costs. It is important to emphasize the economic and social importance of regular road maintenance and to promote actions to achieve sustainable road maintenance with limited public resources [29]. Maintenance is more important than the type of pavement. If pavement is deteriorated, it provides an additional burden for the user due to high uncertainty. In Hungary, paving stones are widely used for cycling routes, although it is evaluated lower than asphalt.

In the questionnaire, the maximum distance for cycling was asked. As it is a continuous variable, a one-way ANOVA test was used to determine if there is significant difference between the districts, the young male cyclists and gender related to the stated maximum distance. Out of the three, both the district $(p<0.001)$ and the gender showed high correlation ( $p=0.002$ ), while the difference between the general population and the young male cyclists were not significant statistically ( $p=0.061)$. The mean - standard error plot by districts can be seen in Fig. 12., the average stated cycling distance in Budapest is around $5 \mathrm{~km}$.

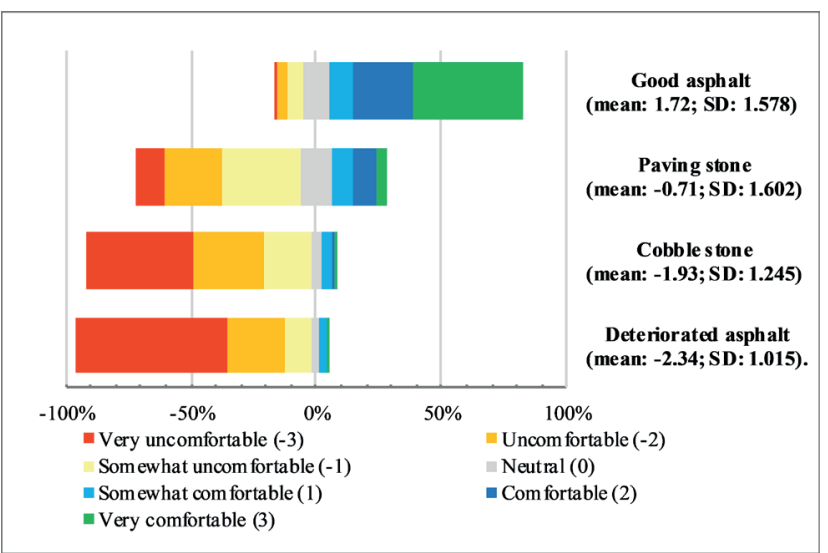

Fig. 11 Comfort of cycling in different surface $(n=672)$ 


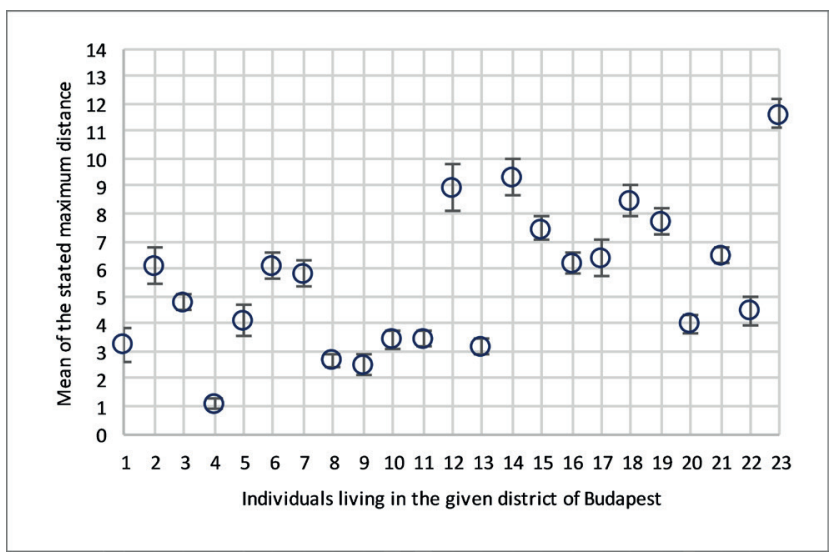

Fig. 12 Mean of the stated maximum distance by districts $(n=1427)$

This research focused on the analysis of answers collected of a European project. As the available resources were limited, the sample size was just adequate. It would have been better, if all the household survey participants had answered these questions. Although the random walk process was applied and the respondents were selected carefully, the statistical representativity of the sample was not $100 \%$. Some of the questions were formulated in a wrong way, but those inadequacies were discussed one by one above.

Despite the above limitations, this research provided some insight into the cyclist behavior in Budapest. Some general remarks and conclusions can be drawn. The next step of this research is to use the stated preference survey of the questionnaires to gain additional details of the behavior and to update the cycling layer of the MTM based on these results.

\section{Conclusions}

A questionnaire was developed as part of the FLOW project in 2016. During a household survey in Budapest, Hungary 1511 answers were collected based on this questionnaire. In this sample 672 respondents were "cyclists", while 839 people were "potential cyclist". After the general household related questions, the main part of the questionnaire explored cycling behavior through 7 questions. As a vast amount of information was collected, there were several possible analyses of the dataset [30,31]. This article only covers some of the main findings, related to the first part of our questionnaire. The stated preference part of the survey will be researched and presented in a different article.
There were some observations which were obvious even from very simple descriptive statistics, but which have implications related to cycling infrastructure and safety:

- the respondents regarded less traffic to be safer and more comfortable,

- the respondents regarded the more segregated cycling infrastructure safer, while the common bus and cycling lane was evaluated worse than the common pedestrian and cycling lane,

- surface type from the best to the worst: good asphalt, paving stone, cobble stone, deteriorated asphalt with potholes,

- the terrain as a factor of mode choice is not important for respondents, which also appears in the answers concerning slopes.

There were several hypotheses formulated and proved during this research:

- there is no significant and provable relationship between the average household income category and the price related parameters,

- the main transport mode has significant effect on cost sensitivity,

- the two groups (cyclists and potential cyclists) answered the question about cycling in general in a significantly different way,

- the perceived comfort and safety of the same type of cycling infrastructure is highly correlated,

- the young male cyclist group perceives safety related aspects differently than the entire population,

- the young male cyclist group is less affected by the slopes of the cyclist infrastructure,

- males and females display significant difference in the stated maximum cycled distance.

Based on the previously described statistical analysis, we can state that the perceived safety is very important in the willingness of cycling. Due to the difference in user groups, the cyclist infrastructure has a varied degree of importance. For cyclist in Budapest a well-maintained cycling infrastructure is extremely important and has high effect on mode choice.

\section{Acknowledgements}

The authors would like to express their gratitude for the transport modelling team at BKK for their help providing background data, especially Mr. Tamás Halmos, whose help and ideas are very much appreciated. 


\section{References}

[1] Torres, M., Silva, L. T., Santos, L., Mendes, J. F. G. "Saúde e bem-estar em meio urbano: das políticas à prática" (Health and well-being in urban environment: From policies to pratice), Revista Portuguesa de Saúde Pública, 31(1), pp. 95-107, 2013.

https://doi.org/10.1016/j.rpsp.2013.04.001

[2] de Chardon, C. M. "The contradictions of bike-share benefits, purposes and outcomes", Transportation Research Part A: Policy and Practice, 121, pp. 401-419, 2019.

https://doi.org/10.1016/j.tra.2019.01.031

[3] Garrard, J. "Active transport: Children and young people, An Overview of Recent Evidence", 2009. [online] Available at: https:// www.vichealth.vic.gov.au/media-and-resources/publications/ active-transport-children [Accessed: 23 March 2020]

[4] World Health Organization "Global health risks: mortality and burden of disease attributable to selected major risks", WHO Press, Geneva, Swizerland, 2009. [pdf] Available at: https:/apps.who.int/ iris/handle/10665/44203 [Accessed: 23 March 2020]

[5] OECD/International Transport Forum "Cycling, Health and Safety", OECD Publishing/ITF, Paris, France, 2013.

https://doi.org/10.1787/9789282105955-en

[6] Veryard, D., Perkins, S. "Integrating Urban Public Transport Systems and Cycling", presented at Summary and Conclusions of the ITF Roundtable on Integrated and Sustainable Urban Transport, Tokyo, Japan, April, 24-25, 2017. [online] Available at: https:// www.itf-oecd.org/sites/default/files/docs/integrating-urbanpublic-transport-systems-cycling-roundtable-summary_0.pdf [Accessed: 23 March 2020]

[7] Fenton, B., Nash, A., Wedderburn, M. "Walking, Cycling and Congestion - Implementer's Guide to Using the FLOW Tools for Multimodal Assessments", 2018. [online] Available at: http:// h2020-flow.eu/fileadmin/user_upload/flow_D_3.5_Implementers_ Guide_multimodal_approach_EN.pdf[Accessed: 23 March 2020]

[8] FLOW Project "15 Quick Facts for Cities. Brussels", 2017. [online] Available at: http://h2020-flow.eu/fileadmin/user_upload/ Deliverables/15_quick_facts_eng_FINAL.pdf [Accessed: 23 March 2020]

[9] Woodcock, J., Givoni, M., Morgan, A. S. "Health Impact Modelling of Active Travel Visions for England and Wales Using an Integrated Transport and Health Impact Modelling Tool (ITHIM)", PLOS ONE, 8(1), Article number: e51462, 2013. https://doi.org/10.1371/journal.pone.0051462

[10] Aldred, R., Woodcock, J., Goodman, A. "Does More Cycling Mean More Diversity in Cycling?", Transport Reviews, 36(1), pp. 28-44, 2016.

https://doi.org/10.1080/01441647.2015.1014451

[11] Rudolph, F., Mátrai, T. "Congestion from a Multimodal Perspective", Periodica Polytechnica Transportation Engineering, 46(4), pp. 215221, 2018. https://doi.org/10.3311/PPtr.12048

[12] Saw, K., Das, A. K., Katti, B. K., Joshi, G. J. "Travel Time Estimation Modelling under Heterogeneous Traffic: A Case Study of Urban Traffic Corridor in Surat, India", Periodica Polytechnica Transportation Engineering, 47(4), pp. 302-308, 2018 https://doi.org/10.3311/pptr.10847
[13] Kager, R., Harms, L. "Synergies from Improved Bicycle-Transit Integration Towards an Integrated urban mobility system", presented at Roundtable on Integrated and Sustainable Urban Transport, Tokyo, Japan, April, 24-25, 2017. [online] Available at: https://www.itf-oecd.org/file/16904/download?token=z4vbf7mZ [Accessed: 23 March 2020]

[14] Berki, Z. "A személyiközlekedési adatfelvételeken alapuló modellek fejlesztése", $\mathrm{PhD}$ Thesis, Budapest Müszaki és Gazdaságtudományi Egyetem, 2008. [online] Available at: http://hdl.handle.net/10890/660 [Accessed: 23 March 2020] (in Hungarian)

[15] Bocz, P., Kisgyörgy, L., Vasvári, G. "Etraffic - an Open Access Transportation Model", Periodica Polytechnica Civil Engineering, 61(3), pp. 564-568, 2017. https://doi.org/10.3311/PPci.9355

[16] Coelho, Jr., E. M., Teixeira Vilas, G., Pereira Da Silva, K. H., Pereira, R. V. "Impactos Positivos Das Implementações De Ciclovias, Ciclofaixas E Faixas Compartilhadas No Município De São Paulo" (Positive Impacts of Implementations of Bike Paths, Cycle Bands and Shared Bands in the Municipality of São Paulo), presented at ENGEMA, São Paulo, Brazil, Dec, 5-6, 2016. (in Portuguese)

[17] e Castro, C. M. S., Barbosa, H. M., de Oliveira, L. K. "Análise do potencial de integração da bicicleta com o transporte coletivo em Belo Horizonte" (Analysis of the potential integration of cycling with public transport in Belo Horizonte), Journal of Transport Literature, 7(2), pp. 146-170, 2013. (in Portuguese) https://doi.org/10.1590/s2238-10312013000200008

[18] de Hartog, J. J., Boogaard, H., Nijland, H., Hoek, G. "Do the Health Benefits of Cycling Outweigh the Risks?", Environmental Health Perspectives, 118(8), pp. 1109-1116, 2010.

https://doi.org/10.1289/ehp.0901747

[19] Elvik, R. "The non-linearity of risk and the promotion of environmentally sustainable transport", Accident Analysis and Prevention, 41(4), pp. 849-855, 2009.

https://doi.org/10.1016/j.aap.2009.04.009

[20] Panis, L.I., de Geus, B., Vandenbulcke, G., Willems, H., Degraeuwe, B., Bleux, N., Mishra, V., Thomas, I., Meeusen, R. "Exposure to particulate matter in traffic: A comparison of cyclists and car passengers", Atmospheric Environment, 44(19), pp. 2263-2270, 2010. https://doi.org/10.1016/j.atmosenv.2010.04.028

[21] Barnes, G., Krizek, K. "Estimating Bicycling Demand", Transportation Research Record: Journal of the Transportation Research Board, 1939(1), pp. 45-51, 2005. https://doi.org/10.1177/0361198105193900106

[22] Buehler, R., Pucher, J. "Cycling to work in 90 large American cities: New evidence on the role of bike paths and lanes", Transportation, 39(2), pp. 409-432, 2012. https://doi.org/10.1007/s11116-011-9355-8

[23] Pucher, J., Buehler, R. "Cycling towards a more sustainable transport future", Transport Reviews, 37(6), pp. 689-694, 2017. https://doi.org/10.1080/01441647.2017.1340234

[24] DiGioia, J., Watkins, K. E., Xu, Y., Rodgers, M., Guensler, R. "Safety impacts of bicycle infrastructure: A critical review", Journal of Safety Research, 61, pp. 105-119, 2017. https://doi.org/10.1016/j.jsr.2017.02.015 
[25] Monsere, C. M., McNeil, N., Dill, J. "Multiuser Perspectives on Separated, On-Street Bicycle Infrastructure", Transportation Research Record: Journal of the Transportation Research Board, 2314(1), pp. 22-30, 2013.

https://doi.org/10.3141/2314-04

[26] Modell TERCETT Konzorcium "Egységes Forgalmi Modell (EFM) - Budapest és Agglomerációjának Teljes Területére, Modellezési és Használati Útmutató" (Unified Traffic Model (UTM) - Modeling and Usage Guide for the Entire Area of Budapest and its Agglomeration), BKK, Budapest, Hungary, 2015. (in Hungarian)

[27] FLOW Project "The Role of Walking and Cycling in Reducing Congestion: A Portfolio of Measures", Brussels, Belgium, 2016. [online] Available at: http://h2020-flow.eu/uploads/tx_news/ FLOW_REPORT_-_Portfolio_of_Measures_v_06_web.pdf [Accessed: 23 March 2020]

[28] Cameron, A. C., Trivedi, P. K. "Microeconometrics, Methods and Applications", New Cambridge University Press, New York, NY, USA, 2005. [online] Available at: https://www.cambridge.org/hu/ academic/subjects/economics/econometrics-statistics-and-mathematical-economics/microeconometrics-methods-and-applications?format=HB\&isbn=9780521848053 [Accessed: 23 March 2020]
[29] Burningham, S., Stankevich, N. "Why road maintenance is important and how to get it done", The World Bank, Washington, DC, USA, Rep. 33925, 2005. [online] Available at: http://documents. worldbank.org/curated/en/971161468314094302/pdf/339250rev.pdf [Accessed: 23 March 2020]

[30] Munro, C. "National Cycling Participation Survey, South Australia", Austroads Ltd., Sydney, Australia, 2017. [online] Available at:https:// austroads.com.au/resources/documents/supporting-documents/corporate-reports/AP-C91-17_Cycling_Participation_Survey_2017_ SA.pdf [Accessed: Day Month Year]

[31] Li, Z., Wang, W., Yang, C., Ragland, D. R. "Bicycle commuting market analysis using attitudinal market segmentation approach", Transportation Research Part A: Policy and Practice, 47, pp. 56-68, 2013.

https://doi.org/10.1016/j.tra.2012.10.017 